\title{
PREFERRED S YSTEM OF MEDICINE AND REASONS OF SELF MEDICATION AMONG COLLEGE STUDENTS IN MALWA REGION OF PUNJAB
}

\author{
${\text { Gupta Vikas }{ }^{1 *} \text {, Bansal Parveen }}^{2}$, Manhas Rajeev $^{3}$, Singh Zora ${ }^{4}$, Ghaiye Pankaj ${ }^{5}$ \\ ${ }^{1}$ University Centre of Excellence in Research, Baba Farid University of Health Sciences, Faridkot, India \\ ${ }^{2}$ Department of Biochemistry, PGIMER, Chandigarh, India \\ ${ }^{3}$ University Library and Informatics Division, BFUHS, Faridkot, India \\ ${ }^{4}$ Department of Anatomy, GGSMCH, Faridkot, India \\ ${ }^{5}$ Akal College of Pharmacy and Technical Education, Mastuana Sahib, San grur, India \\ "Corresponding Author's: E-mail: vikas_4308@ rediffmail.com
}

Received 13 Oct 2011; Revised 24 Nov 2011; Accepted 30 Nov 2011, Available online 10 Dec 2011

\begin{abstract}
The objective of this study was to describe and examine the system of medicine used by college students, awareness, reasons behind self medication, drug information resources, danger findings and knowledge of drug profile. Samples of 3001 young students belonging to Malwa region of Punjab were randomly selected. An inclusion criterion was 16-30 years. A total of 40 students were excluded in accordance with the exclusion criteria like incomplete information. About $55.18 \%$ students had a positive trust in allopathic medicines, $58.91 \%$ students learn self medication from doctors prescriptions provided during their prior illness. $50.08 \%$ students were aware about drug interaction. The results are based on feed backs which were provided by respondents included in study. The results show that percentage of self medication might change along with locality and region. The prevalence of self medication among college students in Malwa region of Punjab is high. This descriptive survey shows that medical students had good knowledge about appropriate self medication than non-medical students. A number of students consult parents, books, friends and advertisements for drug information.
\end{abstract}

Key words: Self medication, College students, Medicines, Punjab

\section{INTRODUCTION}

Self medication is the use of nonprescription medicines by people through using their own initiative ${ }^{1}$. It has also been defined as obtaining and consuming medication without professional supervision, which comprises of acquiring medicines without a prescription, purchasing drugs by resubmitting/ reutilizing an old prescription, taking medicines on advice of relative or others, or consuming leftover medicines already available at home ${ }^{2}$. Some government bodies are encouraging self-care of minor illnesses, including self-medication ${ }^{3}$. Patient empowerment is viewed as a positive step in the development of the relationship between patient and healthcare provider and is considered as an important health policy concept ${ }^{4}$. In several studies it has been found that inappropriate selfmedication results in wastage of resources, increases resistance of pathogens and generally entails serious health hazards such as adverse drug reactions, prolonged suffering and drug dependence 5 . On the other hand, if done appropriately, self-medication can readily relieve acute medical problems, can save the time spent in waiting to see a doctor, may be economical and can even save lives in acute conditions ${ }^{6}$. It is now accepted that self-care in the form of responsible self-medication can be beneficial for patients, healthcare providers, the pharmaceutical industry and governments. The World Health Organization (WHO) has also pointed out that responsible self-medication can help prevent and treat ailments that do not require medical consultation and provides a cheaper alternative for treating common ill-nesses ${ }^{7}$. However, it is also recognized that self-medication must be accompanied by appropriate health in-formation ${ }^{8}$. Studies on self-medication are influenced by many factors, such as education, family, society, law, availability of drugs and exposure to advertisements $^{9}$. A high level of education and professional status has been mentioned as predictive factors for self-medication ${ }^{10}$. The reasons for selfmedication mentioned in the literature are mild illness, previous experience of treating similar illness, economic considerations and a lack of availability of healthcare personnel. The most common medications used for selfmedication are analgesics and antimicrobials ${ }^{11}$.

The present study was undertaken to evaluate the awareness of danger finding, source of drug information, trust in medicinal system and reasons behind self medication.

\section{SUBJECTS AND METHODS}

This study was a questionnaire-based survey approved by the Chairman of University Research and Development Committee. A self developed, pre-validated questionnaire consisting of both open-ended and closed-ended items were used. The study population comprised college students of Malwa region of Punjab. All campus students who were willing to participate in the study were enrolled. A brief seminar was given about the nature of study, and the procedure of completing the questionnaire was explained. Agreeable participants completed the questionnaire in the college campus.

Samples of 3001 students were selected randomly from thirty institutions, 16 non-medical institutes and 14 medical institutes of Malwa region of Punjab. The inclusion criteria for the selection of students was 16 years and above. Out of all 40 students were excluded in 
Gupta et al

Journal of Drug Deli very \& Therapeutics; 2011, 1(2): 27-29

accordance with the exclusion criteria like incomplete information. The questionnaire consisted of questions on type of medicine system, reasons of self medication, awareness of danger finding and source of drug information, The results are based upon the data obtained from 2961 (98.66\%) students. The prevalence of self medication was reported as percentages. The survey was descriptive and data was summarized as counts and percentages, some of the questions had multiple options to choose from, therefore the sum total of percentage is not always $100 \%$.

\section{RES ULTS}

\section{Baseline characteristics of participants}

All the students $(n=3001)$ responded to the questionnaires, of whom 40 were excluded in accordance with the exclusion criteria like incomplete information. Remain ing 2961 (98.66\%) student's questionnaires were considered for evaluation. The non-medical students $(n=1661)$ and medical students $(n=1340)$ responded to the questionnaires, of whom 32 and 8 respectively were excluded in accordance with the exclusion criteria like incomplete information. Remaining 1629(98.07\%) and $1332(99.40 \%)$ student's questionnaires were considered for evaluation.

In non medical institutes $754(45.39 \%)$ males and 907 $(55.61 \%)$ females participated in the study while in medical institutes 309 (23.06\%) males and 1031 (76.94\%) females participated in the study.

\section{Trust in medicine system}

Most of the students had a trust in Allopathic medicine system $(55.18 \%)$ and the percentage of students favoring Homeopathy and Ayurvedic system was $27.86 \%$ and $23.37 \%$ respectively. Students also had trust in other system of medicine like Naturopathy, Chinese system of medicine, Siddha system of medicine, Acupuncture $(4.74 \%)$ etc. The division of non-medical and medical students as per trust in different system of medicines has been listed (Table1)

Table 1: Trust in medicine system

\begin{tabular}{|l|c|c|}
\hline \multirow{2}{*}{$\begin{array}{c}\text { Trust in } \\
\text { medicine } \\
\text { system }\end{array}$} & $\begin{array}{c}\text { Non- } \\
\text { Medical }\end{array}$ & Medical \\
\cline { 2 - 3 } & $\begin{array}{c}\text { Respondents } \\
\text { \% }\end{array}$ & $\begin{array}{c}\text { Respondents } \\
\text { \% }\end{array}$ \\
\hline Allopathic & 49.11 & 61.26 \\
\hline Homeopathic & 28.85 & 26.88 \\
\hline Ay urvedic & 23.69 & 23.05 \\
\hline Unani & 0.61 & 0.30 \\
\hline Others & 5.59 & 3.90 \\
\hline
\end{tabular}

\section{Pre valent reasons of self-medication}

The non-medical and medical respondents perceived several advantages of self medication were listed in Table 2. The most important reasons given by subjects were quick relief $(39.93 \%)$, no need to visit doctor for minor illness (33.18\%), time saving (21.70\%), learning opportunity $(10.42 \%)$,economical cure $(10.04 \%)$ and unavailability of doctor in about $9.5 \%$ cases.

Table 2: Prevalent reasons of self-medication

\begin{tabular}{|l|l|l|}
\hline \multirow{2}{*}{ Reasons } & Non-Medical & Medical \\
\cline { 2 - 3 } & Respondents \% & Respondents \% \\
\hline Time Saving & 17.74 & 25.67 \\
\hline Economical & 9.88 & 10.21 \\
\hline Quick Relief & 37.45 & 42.42 \\
\hline Learning opportunity & 7.49 & 13.36 \\
\hline Ease and convenience & 4.73 & 10.58 \\
\hline Crowd avoidance & 5.28 & 5.55 \\
\hline Unavailability of doctor & 7.98 & 11.04 \\
\hline No need to visit doctor for minor illness & 29.59 & 36.78 \\
\hline
\end{tabular}

\section{Drug infor mation}

The data reveals that $58.91 \%$ students learned self medication from doctor's prescriptions provided during their prior illness. The information from parents, books, friends and advertisements comprised 19.64\%, $12.51 \%$, $8.50 \%$ and $6.34 \%$ respectively guided the students for self medication. The sources of information about drugs used in self medication by non-medical and medical students were listed in Table 3.

Table 3: Source of information about drugs used in self medication by students

\section{Danger findings}

\begin{tabular}{|l|l|l|}
\hline \multirow{2}{*}{ Source of Drug information } & Non-Medical & Medical \\
\cline { 2 - 3 } & Respondents \% & Respondents \% \\
\hline Doctor & 53.04 & 64.79 \\
\hline Friends & 9.58 & 7.43 \\
\hline Parents & 26.89 & 12.39 \\
\hline Pharmacist & 3.07 & 3.53 \\
\hline Books & 6.63 & 18.39 \\
\hline Advertisements & 7.06 & 5.63 \\
\hline Others & 3.62 & 5.40 \\
\hline
\end{tabular}

From the data $1.24 \%$ students committed that they were alcoholic and only $0.59 \%$ were smokers. About $2.27 \%$ students were having chronic problems which were non communicable diseases. Awareness about drug interaction with alcohol, smoking, chronic diseases and others with self medicated medicines was $50.08 \%$ and knowledge about profile of the drug 
which was taken up by self medication practice was $46.31 \%$. Knowledge about danger finding in non-medical and medical students has been listed in Table 4 .

Table 4: Dangers finding that might be dangerous in self medications

\begin{tabular}{|l|l|l|}
\hline \multirow{2}{*}{ Dangers finding } & Non-Medical & Medical \\
\cline { 2 - 3 } & Respondents \% & Respondents \% \\
\hline Alcoholics & 1.29 & 1.20 \\
\hline Smokers & 0.37 & 0.82 \\
\hline Chronic Diseases & 2.45 & 2.10 \\
\hline Awareness about drug interactions & 43.40 & 56.76 \\
\hline Knowledge of drug profiles & 32.72 & 59.91 \\
\hline
\end{tabular}

\section{DISCUSS ION}

This type of study, using a self administered questionnaire, is largely dependent upon information given by respondents. Although students were encouraged to complete the questionnaire independently, mutual influence between pupils could not be entirely ruled out. However, given the high level of response, the results should closely approximate the behavior of the adolescent students in Malwa region of Punjab. The pharmacist's role is mainly seen as that of a drug sales man rather than that of a healthcare provider. Patient education and awareness campaigns are necessary to promote the role of the pharmacist in India. Students with a previous experience and with mild illness were more likely to practice self medication. This has implications, because many diseases have similar symptoms and a person using previous experience may be exposed to the dangers of misdiagnosis and cons equently wrong treatment.

Out of 2961 respondents medical college respondent had good knowledge than non medical college respondent about profile of the drug which was taken up by self medication practice. They were aware of the dose of drug, duration of therapy, toxic dose of drug, active constituents, indications and side effects of commonly used medicine. Major reasons of self medication at student level were quick relief, no need advice from prescriber for minor illness, time saving, learing opportunity and economical etc. Most of the respondent has positive attitude in self medication in minor illness. However, minor illness

\section{REFERENCES}

1. Hughes CM, McElnay JC, Fleming GF, Benefits and risks of self medication, Drug Safety, 2001, 24, 1027-1037.

2. Zafar SN, Reema S, Sana W, Akbar JZ, Talha V, Mahrine S, Wajeeha Y, Saman S, Sarah S, Self medication amongst university students of Karachi: prevalence, knowledge and attitudes, J Pak Med Assoc., 2008, 58, 214-17.

3. Porteous T, Bond C, Hannaford P, Sinclair H, How and why are non-prescription analgesics used in Scotland? Fam Pract., 2005, 22, 78-85.

4. World Health Organization: The role of the pharmacist in self-care and self-medication. Report of the 4th WHO Consultative Group on the role of the pharmacist in health care system, 1998, http://www.who.int/medicines/ library/dap/who-dap-98-13/who-dap-98-13. pdf.

5. Kiyingi KS, Lauwo JAK, Drugs in home: dan-ger and waste, World Health Forum 1993, 14, 381-384.

6. Clavinjo HA, Self-medication during pregnancy, World Health Forum, 1995, 16, 403-404.

7. World Health Organization: Report of the WHO Expert Committee on National Drug Policies, 1995, symptoms may cause major illness if not diagnosed properly.

\section{CONCLUSION:}

This descriptive survey shows that the majority of students had a poor knowledge about appropriate self-medication while the knowledge of the benefits and risks was not adequate. Thus, to avoid or minimize the dangers of self medication, firstly the students should be educated about the dangers of indiscriminate use of drugs, secondly, the drug authorities must insist on drugs being supplied by the chemist only on a valid prescription, thirdly, a proper statutory drug control must be implemented, rationally restricting on the availability of drugs to the public. The authors also think that lack of good health services at study centers is also one of the prevalent reasons of self medication.At the same time lack of sufficient money to go and consult to doctor may be another reason for self medication however the data results are contrary to the presumed results. The above three measures would definitely reduce the incidence of drug-related misfortunes and help in maintaining good health of the individual and society also.

\section{ACKNOWLEDEMENT}

Authors thanks Hon'ble Vice Chancellor, Baba Farid University of Health Sciences, Faridkot (BFUHS) for his financial assistance and encouragement to complete this survey. Authors also express their gratitude to the students for extending their support and giving information.

http://www.who.int/medicines/ library/dap/who-dap- 959/who-dap-95.9. shtml.

8. Kafle KK, Gartulla RP, Self-medication and its impact on essential drugs schemes in Nepal: a sociocultural research project,

1993, http://www.who.int/medicines/library/dap/who-dap-9310/who-dap-93-10.shtml.

9. Hebeeb GE, Gearhart JG, Common patient symptoms: patterns of self-treatment and pre-vention, J Miss State Med Assoc, 1993, 34, 179- 181.

10. Martins AP, Miranda AC, Mendes Z, Soares MA, Ferreira $\mathrm{P}$, Nogueira A, Self-medication in a Portuguese urban population: a prevalence study, Pharmacoepidemiol Drug Safety, 2002, 11, 409-414.

11. Shankar PR, Partha P, Shenoy N, Self-medication and nondoctor prescription practices in Pokhara valley, Western Nepal: a questionnaire-based study, BMC Family Practice, 2003, 3, 17-24. 